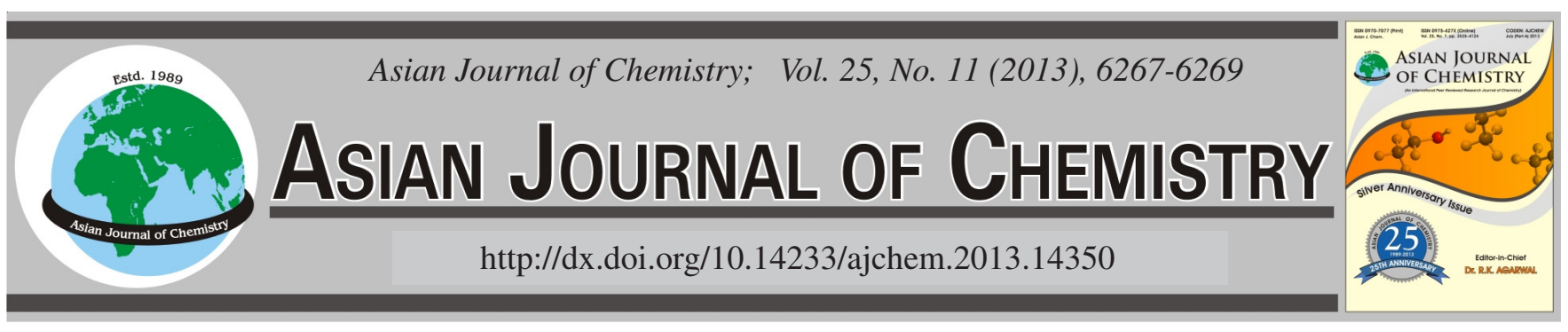

\title{
Application of Graphene as a Sorbent for Preconcentration and Determination of Trace Amounts of Lead in Water Samples Prior to Flame Atomic Absorption Spectrometry
}

\author{
Yan-Li Dong, Qi-Feng Liu, Xin Zhou, Shu Tao Gao, Jing Ci Li and Jing Jun Ma*
}

Hebei Key Laboratory of Bioinorganic Chemistry, College of Sciences, Agricultural University of Hebei, Baoding, P.R. China

*Corresponding author: Fax: +86 312 7528292; Tel: +86 312 7528291; E-mail: mjjwjpmartin@sina.com

Graphene, a novel class of carbon nanostructures, has great promise for use as sorbent materials because of its ultrahigh specific surface area. A new method using a column packed with graphene as sorbent was developed for the preconcentration of trace amounts of lead prior to its determination by flame atomic absorption spectrometry. Under the optimal conditions, the calibration graph was linear in the concentration range of $10-600 \mu \mathrm{g} \mathrm{L}-1$ with a detection limit of $0.54 \mu \mathrm{g} \mathrm{L}^{-1}$. The relative standard deviation for ten replicate measurements of $400 \mu \mathrm{g} \mathrm{L}^{-1}$ of $\mathrm{Pb}$ was $3.33 \%$. This proposed method was successfully applied to tap water, river water and sea water and accuracy was assessed through the analysis of certified reference water or recovery experiments.

Key Words: Graphene, Solid-phase extraction, Preconcentration, Flame atomic absorption spectrometry, Lead.

\section{INTRODUCTION}

Graphene, a new class of carbon nanomaterial, has recently sparked much interest due to its unique strict two-dimensional nanostructure ${ }^{1-3}$. Compared with other graphitic forms, graphene possesses extraordinary electronic, thermal and mechanical properties such as ultrahigh specific surface area, good thermal conductivity, fast mobility of charge carriers and high values of Young's modulus and fracture strength ${ }^{4-7}$. To date, graphenebased materials are applied in many fields, such as sensors and biosensors ${ }^{8}$, energy storage ${ }^{9,10}$, drug delivery ${ }^{11,12}$, catalytic $^{13,14}$ and gas separation ${ }^{15}$. Besides, graphene is an electron-rich, hydrophobic nanomaterial with large specific area and $\pi-\pi$ electrostatic stacking property ${ }^{16,17}$. These features make graphene very attractive as a wonderful adsorbent or extraction material. In fact, the solid phase extraction technique using graphene as a novel adsorbent has been developed by Liu et al..$^{18}$, for the determination of eight chlorophenols in aqueous samples. They demonstrated that the preconcentration technique is an efficient, simple and nonexpensive extraction procedure for HPLC analysis. We extend its application to inorganic analysis and obtained the consistent conclusion.

In the present work, the solid phase extraction using graphene as absorbent in a column combined with flame atomic absorption spectrometry was demonstrated. The applicability of this approach was validated for the determination of $\mathrm{Pb}$ in water samples. Lead was selected for the evaluation of this procedure, because it is a toxic heavy metal that appears in the environment mainly due to industrial processes. Therefore, it is essential to develop sufficiently sensitive and reproducible analytical methods for the precise monitoring of this element at trace level.

\section{EXPERIMENTAL}

A Shimadzu (Kyoto, Japan) Model AA-6300C atomic absorption spectrometer equipped with deuterium background correction was used in the experiment. A pH3-3C digital $\mathrm{pH}$ meter equipped with a combined glass-calomel electrode (Hangzhou Dongxing Instrument Factory, Hangzhou, China) was used for $\mathrm{pH}$ adjustment. The solid phase extraction experiments were performed on an Agilent vacuum manifold processing station with a gast vacuum pump (Tegent Technology Ltd. Shanghai, China). The empty SPE columns (3.0 mL) and solid phase extraction frits were purchased from Agilent.

All reagents used were of analytical reagent grade. Deionized water was used in the preparation of all solutions. All glassware and columns were kept in $10 \%$ nitric acid for at least $24 \mathrm{~h}$ and subsequently washed four times with deionized water before application. Graphene was prepared according to the method in literature ${ }^{19,20}$.

Graphene $(30.0 \mathrm{mg})$ was placed in a $3.0 \mathrm{~mL}$ SPE column using an upper frit and a lower frit to avoid adsorbent loss. Prior to extraction, the column was preconditioned with $10 \mathrm{~mL}$ methanol and $10.0 \mathrm{~mL}$ deionized water, respectively. The column was then conditioned to the desired $\mathrm{pH}$ with $5 \mathrm{~mL}$ of $0.2 \mathrm{~mol} \mathrm{~L}^{-1}$ phosphate buffer solution. 
$100 \mathrm{~mL}$ of sample solution containing $400.0 \mu \mathrm{g} \mathrm{\textrm {L } ^ { - 1 }}$ of $\mathrm{Pb}$ was prepared. APDC solution $\left(0.5 \mathrm{~mL}, 5.0 \times 10^{-2} \mathrm{~mol} \mathrm{~L}^{-1}\right)$ was added and the $\mathrm{pH}$ value was adjusted to 6.0 with phosphate buffer solution. The resulting sample solution was passed through the column at a flow rate of $2.0 \mathrm{~mL} \mathrm{~min}^{-1}$. After the solution passed completely, the column was rinsed with 5.0 $\mathrm{mL}$ water and the analytes retained on the column were eluted with $2.0 \mathrm{~mL}$ of $1.0 \mathrm{~mol} \mathrm{~L}^{-1} \mathrm{HNO}_{3}$ in methanol at a flow rate of $2.0 \mathrm{~mL} \mathrm{~min}^{-1}$. The analyte ions in the eluent were determined by FAAS.

\section{RESULTS AND DISCUSSION}

In the SPE procedure, it was found that the recovery was relatively low in the preliminary experiments. Therefore, APDC was used for the chelating of lead ion. The $\mathrm{pH}$ plays a unique role on metal-chelate formation and subsequent extraction and consequently, is a main parameter for SPE. A series of experiments was performed by adjusting the $\mathrm{pH}$ from 2.0-10.0 with nitric acid, ammonium acetate, phosphate and ammonium chloride. The results revealed that the absorbance is nearly constant in the $\mathrm{pH}$ range of 5.0-7.0. The progressive decrease in $\mathrm{Pb}$ extraction at low $\mathrm{pH}$ is due to the competition of hydrogen ion with analyte for the reaction with APDC. Accordingly, $\mathrm{pH} 6.0$ was selected for subsequent work and real sample analysis.

The effect of the flow rate of the sample and eluent solutions on the recoveries of $\mathrm{Pb}$ on graphene was examined in the range of $0.5-5.0 \mathrm{~mL} \mathrm{~min}^{-1}$. The flow rate of the sample and eluent solutions had no obvious influence on the quantitative recoveries of analytes at the range of 0.5-4.0 and 0.5$2.0 \mathrm{~mL} \mathrm{~min}^{-1}$, respectively. Therefore, $2.0 \mathrm{~mL} \mathrm{~min}^{-1}$ was chosen as the flow rate of the sample and eluent solutions in subsequent experiments. The sample volume was also investigated in the range of 25-800 mL. The results demonstrated that the quantitative recovery $(>95 \%)$ of $\mathrm{Pb}^{2+}$ was obtained when the sample volume was lower than $500 \mathrm{~mL}$ Considering the enrichment factor and analysis time, $100 \mathrm{~mL}$ was ultimately chosen for routine analysis.

Various eluent solutions were used for desorption of metalAPDC chelates from graphene. It was found that the recoveries of $\mathrm{Pb}$ were not quantitative when $\mathrm{HCl}, \mathrm{HNO}_{3}$ and $\mathrm{NaOH}$ was used as eluent solely. Quantitative recovery (>95\%) for analyte ions was obtained only with $1.0 \mathrm{~mol} \mathrm{~L} \mathrm{HNO}_{3}$ in methanol. The effect of eluent volume on the recovery of $\mathrm{Pb}$ was also studied by using $1.0 \mathrm{~mol} \mathrm{~L}^{-1} \mathrm{HNO}_{3}$ in methanol; it was found that quantitative recoveries could be obtained with $2.0-4.0 \mathrm{~mL}$ of $1.0 \mathrm{~mol} \mathrm{~L}^{-1} \mathrm{HNO}_{3}$ in methanol. Therefore, the volume of $2.0 \mathrm{~mL}$ of $1.0 \mathrm{~mol} \mathrm{~L}^{-1} \mathrm{HNO}_{3}$ in methanol was used in the following experiments.

As other condition was optimized, it was very crucial to pay more attention to the coexisting ions because they may influence the enrichment in most cases. Herein, an investigation was performed for this purpose. The experiment result 10000-, 10000-, 100-, 100-, 100-, 100-, 100-, 100-, 50-, 50-, 40-, 40-, 40-, 30-, 30- and 10000-folde (concentration ratio of ions/ $\mathrm{Pb}$ ) of $\mathrm{Na}^{+}, \mathrm{K}^{+}, \mathrm{Mg}^{2+}, \mathrm{Ca}^{2+}, \mathrm{Cu}^{2+}, \mathrm{Ba}^{2+}, \mathrm{Al}^{3+}, \mathrm{Cr}^{3+}, \mathrm{Mn}^{2+}$, $\mathrm{Fe}^{3+}, \mathrm{Ag}^{+}, \mathrm{Cd}^{2+}, \mathrm{Zn}^{2+}, \mathrm{Ni}^{2+}, \mathrm{Co}^{2+}$ and $\mathrm{CH}_{3} \mathrm{COO}^{-}\left(\mathrm{HCO}_{3}{ }^{-}, \mathrm{NO}_{3}^{-}\right.$, $\mathrm{Cl}^{-}$) had no impact on the extraction of $\mathrm{Pb}$ with a concentration of $400 \mu \mathrm{g} \mathrm{\textrm {L } ^ { - 1 }}$.
A series of experiments were employed for achieving the parameters of analytical performance. Under the optimal conditions, it was found that the calibration equation, an excellent linear range, detection limit and precision were $\mathrm{A}=$ $8.16 \times 10^{-4} \mathrm{C}+0.0036,10-600 \mu \mathrm{g} \mathrm{L} \mathrm{L}^{-1}(\mathrm{R}=0.9991), 0.54 \mu \mathrm{g} \mathrm{L^{-1 }}$ and $3.33 \%\left(400 \mu \mathrm{g} \mathrm{L}^{-1}, \mathrm{n}=10\right)$, respectively.

The procedure was applied to the determination of lead in several water samples and the results along with the recovery for the spiked samples were given in Table- 1 . The recoveries for the addition of different concentrations of lead to water samples were in the range $95.2-99.5 \%$. To verify the accuracy of the proposed procedure, the method was then used for the determination of the content of $\mathrm{Pb}$ in National Standard Reference Material for Environment Water (GSBZ50009-88 and GSB07-1183-2000) after the appropriate dilution. These results are presented in Table-1. A good agreement between the determined values and the certified values was obtained.

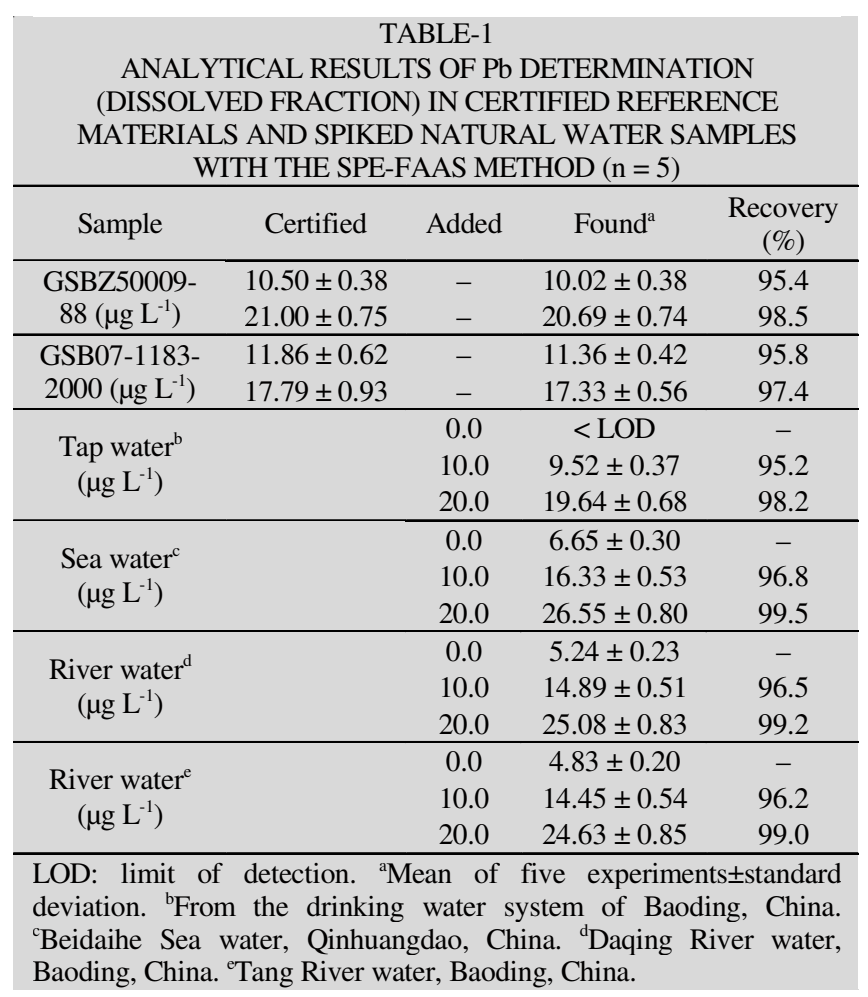

\section{Conclusion}

The proposed solid phase extraction method is easy, safe and economic for the preconcentration and determination of trace amounts of $\mathrm{Pb}$ in different samples. Due to a relatively high preconcentration factor, $\mathrm{Pb}$ at trace level can be determined accurately. The proposed system for $\mathrm{Pb}$ was used for 50 subsequent preconcentration cycles without any loss on the adsorption behaviours of graphene all throughout of the work. Higher recoveries were achieved with graphene than with other adsorbents including $\mathrm{C}_{18}$ silica, graphitic carbon and carbon nanotubes, owing to the large surface area and unique chemical structure of graphene. This work not only proposes a useful method for environmental water samples pretreatment, but also reveals the great potential of graphene as an excellent sorbent material in analytical processes. 


\section{ACKNOWLEDGEMENTS}

This project was sponsored by the Development Foundation of the Department of Education of Hebei Province (No. zh2011128) and the Research Development Foundation of the Agricultural University of Hebei.

\section{REFERENCES}

1. K.S. Novoselov, A.K. Geim, S.V. Morozov, D. Jiang, Y. Zhang, S.V. Dubonos, I.V. Grigorieva and A.A. Firsov, Science, 306, 666 (2004).

2. A.K. Geim and K.S. Novoselov, Nature Mater., 6, 183 (2007).

3. A.K. Geim, Science, 324, 1530 (2009).

4. M.D. Stoller, S.J. Park, Y.W. Zhu, J.H. An and R.S. Ruoff, Nano Lett., 8, 3498 (2008).

5. C. Lee, X.D. Wei, J.W. Kysar and J. Hone, Science, 321, 385 (2008).

6. A.A. Balandin, S. Ghosh, W.Z. Bao, I. Calizo, D. Teweldebrhan, F. Miao and C.N. Lau, Nano Lett., 8, 902 (2008).

7. K.I. Bolotin, K.J. Sikes, Z. Jiang, M. Klima, G. Fudenberg, J. Hone, P. Kim and H.L. Stormer, Solid State Commun., 146, 351 (2008).

8. C.H. Lu, H.H. Yang, C.L. Zhu, X Chen and G.N. Chen, Angew. Chem. Int. Ed., 48, 4785 (2009).
9. J. Yan, T. Wei, B. Shao, Z. Fan, W. Qian, M. Zhang and F. Wei, Carbon, 48, 487 (2010).

10. G.X. Wang, B. Wang, X.L. Wang, J. Park, S.X. Dou, H. Ahn and K. Kim, J. Mater. Chem., 19, 8378 (2009).

11. X.Y. Yang, X.Y. Zhang, Y.F. Ma, Y. Huang, W.S. Wang and Y.S. Chen, J. Mater. Chem., 19, 2710 (2009).

12. Z. Liu, J.T. Robinson, X.M. Sun and H.J. Dai, J. Am. Chem. Soc., 130, 10876 (2008).

13. G.M. Scheuermann, L. Rumi, P. Steurer, W. Bannwarth and R. Mülhaupt, J. Am. Chem. Soc., 131, 8262 (2009).

14. E.J. Yoo, T. Okata, T. Akita, M. Kohyama, J.J. Nakamura and I. Honma, Nano Lett., 9, 2255 (2009).

15. D. Jiang, V.R. Cooper and S. Dai, Nano Lett., 9, 4019 (2009).

16. M.J. Allen, V.C. Tung and R.B. Kaner, Chem. Rev., 110, 132 (2010).

17. D.R. Dreyer, S. Park, C.W. Bielawski and R.S. Ruoff, Chem. Soc. Rev., 39, 228 (2010).

18. Q. Liu, J.B. Shi, L.X. Zeng, T. Wang, Y.Q. Cai and G.B. Jiang, J. Chromatogr. A, 1218, 197 (2011).

19. H.F. Yang, F.H. Li, C.S. Shan, D.X. Han, Q.X Zhang, L. Niu and A. Ivaska, J. Mater. Chem., 19, z4632 (2009).

20. D. Li, M.B. Muller, S. Gilje, R.B. Kaner and G.G. Wallace, Nature Nanotech., 3, 101 (2008) 